\title{
JUPYRA CUNHA MARCONDES: UM VIDEODOCUMENTÁRIO SOBRE SUA VIDA E OBRA
}

Ivanildo Reinaldo de Oliveira' Mylene da Silva SantosFirmino' Paulo José Sereguetti' Suelen Perez Azevedo, Thaisa Sallum Bacco

Faculdade de Comunicação Social “Jornalista Roberto Marinho" de Presidente Prudente da Universidade do Oeste Paulista - UNOESTE

\section{RESUMO}

Este artigo tem como proposta contributiva documentar a trajetória de Jupyra Cunha Marcondes e suas principais contribuições no âmbito cultural para a cidade de Presidente Prudente. A metodologia empregada para a realização deste estudo tem abordagem qualitativa e em seu delineamento optou-se pelo estudo de caso. A pesquisa teve como método a História Oral. Os instrumentos de coleta de dados utilizados foram pesquisa e análise documental e entrevistas em profundidade. A investigação relata que Jupyra Cunha Marcondes é precursora da cultura, dedicando sua vida ao rádio, ao teatro, ao ensino da música e à promoção de festas artísticas e cívicas. Os resultados colhidos estão apresentados no videodocumentário intitulado "Jupyra", de 90 minutos de duração, que contém depoimentos de 23 fontes, entre amigos, ex-alunos, pessoas envolvidas com a cultura e familiares.

Palavras-chave: videodocumentário; Jupyra Cunha Marcondes; Presidente Prudente.

\section{INTRODUÇÃO}

A história de uma cidade é composta por trajetórias individuais que, em diversos momentos, se entrelaçam por seu protagonismo com a sociedade, se perpetuando por décadas na memória social.

Presidente Prudente está próxima de completar seu centenário de fundação, em 2017, e por isso a necessidade de reconhecer algumas pessoas que fizeram parte desse desenvolvimento desde suas primeiras décadas. No cenário cultural encontra-se o nome de Jupyra Cunha Marcondes.

Nascida em 3 de agosto de 1905 na cidade de Franca (SP), filha de um intelectual da época, Francisco Cunha, Jupyra mudou-se com a família para Presidente Prudente em 1923. Na cidade conheceu seu esposo, Paulo Kruger Soares Marcondes, filho de um dos fundadores do município, o coronel José Soares Marcondes.

A atuação de Jupyra na sociedade prudentina iniciou-se com a docência no Colégio São Paulo, quando esteve envolvida nas organizações de festas cívicas e particulares e na promoção de peças teatrais, engajando seus alunos nas apresentações.

A Rádio Difusora PRI-5 também foi seu local de trabalho. Como diretora artística, Jupyra determinava a programação e criava conteúdo para os programas (BENDRATH, 2013). Porém seu 
reconhecimento nacional deu-se a partir do momento em que passou a escrever e adaptar radionovelas na década de 1940 .

Inspirada pelos conselhos dos seus professores de música, Jupyra empenhou-se em fundar o Conservatório Dramático e Musical, em 1952, e proporcionar à população prudentina o contato com a cultura baseada nos grandes centros, como o da capital paulista.

Por que Jupyra tinha intimidade com o campo das artes? O que representou a cidade de Presidente Prudente para Jupyra? Como eram os momentos em família? Quais foram os nomes das artes e música que influenciaram a sua formação? Como era Jupyra como professora? De que forma eram organizadas as primeiras peças teatrais sob sua responsabilidade? $\mathrm{O}$ que representou as radionovelas em sua vida? O que motivou tal senhora a fundar um conservatório dramático e musical? O que sua morte representou para a sociedade?

Essas perguntas foram as que motivaram essa pesquisa, que teve como objetivo geral documentar, por meio da linguagem audiovisual, a trajetória de vida e obra de Jupyra Cunha Marcondes como expoente cultural de Presidente Prudente.

Como caminho metodológico, o estudo apresenta uma abordagem qualitativa, que, para Demo (2000, p.152), é aquela que “[...] faz jus à complexidade da realidade, curvando-se diante dela, não o contrário, como ocorre com a ditadura do método ou a demissão teórica que imagina dados evidentes".

O delineamento desta pesquisa foi o estudo de caso, indicado para a compreensão de fenômenos individuais e sociais, colocando os pesquisadores em maior contato com o que está sendo estudado (GIL, 2010).

Para dar início ao estudo de caso, foi realizada a pesquisa bibliográfica, que abrange toda bibliografia tornada pública, levando-se em consideração o tema de estudo (LAKATOS; MARCONI, 2005).

Além da pesquisa bibliográfica, fez-se necessário colher depoimentos de 23 fontes com a finalidade de conhecer a vida e obra de Jupyra Cunha Marcondes. Nas entrevistas, o método de História Oral forneceu suporte para o desenvolvimento da pesquisa. Pollak $(1992$, p. 2) define como História Oral "[...] a ligação entre memória e identidade social, mais especificamente no âmbito das histórias de vida".

Nesta investigação, as entrevistas em profundidade foram realizadas com três grupos de sujeitos. O primeiro deles corresponde aos familiares que conviveram com Jupyra Cunha Marcondes. O segundo grupo é formado por ex-alunos e amigos que tiveram contato profissional 
com ela. Por fim, o terceiro grupo é formado por pessoas envolvidas com a cultura na cidade de Presidente Prudente.

Outro instrumento utilizado para a coleta de dados foi a pesquisa e análise de documentos que registraram a atuação de Jupyra Cunha Marcondes no contexto cultural prudentino. Como o próprio nome afirma, a pesquisa documental se refere à identificação, verificação e apreciação de documentos que possam trazer informações sobre o objeto estudado, assim, enriquecendo o trabalho (MOREIRA, 2009).

A fonte documental consultada nesta investigação foi o jornal "O Imparcial" de Presidente Prudente. Página por página, os pesquisadores verificaram os exemplares do impresso de 1939 até 1974, ano da morte de Jupyra Cunha Marcondes. Cada notícia e fotografia encontrada, que se relacionava ao objeto de estudo, foi analisada e contribuiu para confecção do corte teórico desta pesquisa e na produção do videodocumentário. O jornal foi acessado por meio do acervo disponível no Museu e Arquivo Histórico Prefeito Antonio Sandoval Netto de Presidente Prudente. A Escola Municipal de Artes Professora Jupyra Cunha Marcondes também contribuiu com este levantamento de dados oferecendo recortes de jornais e fotografias do seu acervo.

\section{Vida e obra de Jupyra}

Jupyra Cunha Marcondes nasceu em 3 de agosto de 1905 na cidade de Franca (SP), mas deixou seu legado em Presidente Prudente, município para o qual se mudou em 1923, com os pais Maria Etelvina Cunha e Francisco Cunha.

Segundo o jornalista Altino Correia (2013), Francisco Cunha foi fundador do jornal francano "A Tribuna da Franca", e veio para Presidente Prudente a convite de José Soares Marcondes, importante coronel da cidade, para desenvolver a atividade de agrimensor ${ }^{1}$.

De acordo com Pinto (2013), Francisco Cunha, na companhia da esposa Maria Etelvina Cunha e da filha Jupyra Cunha Marcondes, então com 18 anos, desembarcou na cidade de Indiana por intermédio da estrada de ferro, a caminho da nova cidade.

Segundo Lins (1974), não foi agradável para as acompanhantes de Francisco Cunha acostumarem-se em termos psicológicos com o ambiente ao qual foram inseridas. Existiram até mesmo pedidos para regressarem a Franca, no que não foram atendidas por ele.

Tendo em vista a distância entre as cidades de Presidente Prudente e Franca e as dificuldades de transporte e comunicação, Cunha sugeriu à esposa que as duas passassem a residir

\footnotetext{
1 "Ele delimitava terra. Ele vinha, fazia um mapeamento do espaço e fazia loteamento desse espaço. Ele demarcava lotes, com entrada, com saídas, abria estradas, picadas, no caso, abria picadas no meio da mata." (MACEDO, 2013) 
em São Paulo (SP), levando em consideração que sua filha continuava no Colégio Santana ${ }^{2}$ desde 1921 e assim foi feito. Durante um período Jupyra e a mãe ficaram em São Paulo, mas brevemente retornaram a Presidente Prudente.

Em termos educacionais, foi em sua cidade natal, ainda criança, que Jupyra iniciou seus estudos no Grupo Escolar "Francisco Martins". Mesmo longe de Franca, manteve seus estudos de formação musical, tendo como professor o renomado músico Samuel Arcanjo, da capital paulista. Com residência em Presidente Prudente, permaneceu viajando mensalmente para usufruir dos ensinamentos que seu mestre julgava necessitar.

A aproximação entre as famílias Cunha e Marcondes por intermédio dos negócios acabou por reuni-las em uma só por meio do casamento entre Jupyra e Paulo Kruger Soares Marcondes, em 1927. A cerimônia foi realizada na igreja de Nossa Senhora Aparecida, na cidade de Aparecida (SP).

Após o casamento, vieram os filhos Paulo Francisco (10/12/1927), Oswaldo Henrique (27/01/1930), José Roberto (28/01/1931 - falecido em 30/09/2002) e Washington Luiz (04/06/1932), todos batizados em Presidente Prudente, na Paróquia Nossa Senhora Aparecida, na Vila Marcondes (MARCONDES, W., 2013).

Paulo Francisco, o primogênito, casou-se em 1956 com Terezinha Vieira Vinagre, e com ela teve duas filhas: Thereza Christina Vieira Marcondes (3/09/1957) e Virgínia Vieira Marcondes (20/07/1960). Atualmente, vivem na cidade litorânea de Praia Grande (SP). Oswaldo Henrique, o segundo filho, nos dias atuais reside em Ribeirão Preto, e é casado com Maria Esther Fernandes e tem duas filhas: Cassandra Fernandes Marcondes (6/09/1957) e Cintia Fernandes Marcondes (9/09/1959). O terceiro filho, José Roberto, foi casado com Alma Ely Staut Gomes Pinto. Tiveram quatro filhos, porém, um falecido quando bebê. São eles: José Roberto Cunha Marcondes Filho (22/10/1955), Paulo Alfredo Gomes Marcondes (07/06/1959) e Afonso Celso Gomes Marcondes (08/10/1961).

A preocupação e desempenho nos assuntos ligados ao conhecimento e ao intelecto levou Jupyra a seguir no caminho do magistério, mesmo sem nunca ter feito um curso superior. Como professora em Presidente Prudente, durante a década de 1920, ministrou aulas de música e francês no "Colégio São Paulo" e "Fernando Costa", agora conhecido como "IE". No entanto, superava seus limites e também substituía qualquer disciplina que fosse necessário (PINTO, 2013).

\footnotetext{
2 “Com 120 anos de experiência em Educação o Colégio Santana, escola católica das Irmãs de São José, consolida-se na zona norte, no bairro de Santana, como espaço de produção educacional, cultural, social, científica e religiosa, reafirmando a cada ano sua missão de centro vivo de expansão de conhecimentos e desenvolvimento Humano." Os pesquisadores entraram em contato com o Colégio, mas não obtiveram informações sobre o histórico escolar de Jupyra Cunha Marcondes. (ENSINO..., 2013)
} 
Para o filho Oswaldo Marcondes (2013), Jupyra sempre se mostrou à frente de seu tempo, e em meio as aulas passou a ensaiar seus alunos para apresentações teatrais da escola ou de eventos cívicos, como o do dia da Independência do Brasil, o 7 de setembro, ou ainda para o aniversário da cidade de Presidente Prudente, comemorado no dia 14 de setembro.

De acordo com a nora Alma Ely Pinto (2013), a mãe de Jupyra, Maria Etelvina, era a responsável pelas tarefas do lar e também cuidava dos quatro netos. Como professora e organizadora de eventos, Jupyra não tinha muito tempo disponível para a realização destes serviços diários. "[...] Jupyra nunca foi dona de casa, mas sempre a artista da família. Por isso a mãe, Maria Etelvina, cuidou de tudo como pode." (PINTO, 2013)

Não demorou muito para que Jupyra Cunha Marcondes fosse reconhecida e elogiada nas publicações do jornal "O Imparcial". Todas as suas atividades, sejam elas na escola ou à frente do conservatório, eram noticiadas. Não só elas. As qualidades de Jupyra também ganharam destaque. A reportagem do dia 27 de abril de 1943 relata a apresentação da peça "Vitória" escrita pela própria professora, nomeada pelo jornal como "escritora", mais uma qualificação entre as diversas que recebia.

Segundo Pinto (2013), por consequência das eleições de Paulo Marcondes, a família era designada de "alta de Prudente", ou seja, considerados de alto nível pela comunidade prudentina. Macedo (2013) explica que "Paulo foi eleito ${ }^{3}$ por um curto espaço de tempo, pois na época o prefeito ficava em exercício da função por um ano ou dois no máximo. De acordo com ele, os vereadores eram encarregados de eleger o prefeito, e por esse motivo Paulo Marcondes foi eleito por três vezes na década de 1920." (MACEDO, 2013).

Jupyra não se destacava na sociedade apenas por ser considerada "primeira dama" e sim pelos feitos que realizava em prol da cultura. Segundo a nora Mariangela Marcondes (2013), Jupyra era muito ligada aos jovens e tinha um vocabulário próprio para conversar com eles. Por isso sua residência sempre estava repleta de adolescentes, assim como seus próprios filhos.

O respeito com a família parece não diferenciar quando se trata dos funcionários, de acordo com Conceição de Lourdes Pedrosa Alves (2013), que foi empregada doméstica de Jupyra. Lembrar-se da personalidade da ex-patroa é tarefa fácil para Conceição. Ela diz que nunca presenciou Jupyra nervosa ou mal humorada, e sim sempre feliz, amorosa e carinhosa (ALVES, 2013).

\footnotetext{
${ }^{3}$ Paulo Kruger Soares Marcondes governou a cidade de Presidente Prudente três vezes. O primeiro mandato foi de 01/02/1926 - 31/10/1926, a segunda gestão foi de 01/01/1928 - 30/04/1928 e, por fim, seu último governo foi de 01/10/1928 - 31/12/1928 (HISTÓRIA..., 2013) 
Como professora, Jupyra deixou um legado e uma boa lembrança na memória dos exalunos. Para Maria José Marino (2013), a mestre era muito dedicada e atenciosa, porém muito exigente.

O jornalista Neif Taiar (2013) relembra que todos os professores, na época, eram exigentes, porém Jupyra "[...] em particular tinha que manter uma figura respeitosa", por ter uma participação mais evidente na sociedade e na vida da cidade.

Sua preferência pelo idioma francês também levou Jupyra a propagar em suas aulas essa paixão. De acordo com Marino (2013), a professora gostava de ensinar o Hino Nacional da França, La Marselhesa.

Além das áreas teatral e musical, Jupyra atuou como diretora artística na primeira rádio de Presidente Prudente, a Rádio Difusora PRI-5. Ela verificava datas comemorativas que poderiam ser utilizadas na programação e eventos artísticos de Presidente Prudente. "Em um programa dirigido por ela, a PRI-5 foi transmitida pela primeira vez em rede para São Paulo capital." (BENDRATH, 2013)

Jupyra foi reconhecida por escrever radionovelas. Umas das primeiras obras radiofônicas, citadas pelo jornal "O Imparcial”, foi em 1944, precisamente no dia primeiro de junho (LINS, 1974). Foi a radionovela intitulada "Amor de Outono".

De acordo com o filho Washington Marcondes (2013), uma radionovela era gravada em uma única noite, e em no máximo duas horas, e tinha começo, meio e fim. Por seu talento, Jupyra chama atenção de duas grandes rádios, a Rádio Tupi e a Rádio Nacional, ambas do Rio de Janeiro.

Segundo o amigo da família Altino Correia (2013), Jupyra revelou-se em Presidente Prudente como escritora, produtora, e "[...] era considerada uma pessoa que tinha o que contar, tinha o que oferecer" sobre temas voltados à comunidade, e por isso suas radionovelas produzidas aqui eram enviadas para as emissoras locais e para um público regional.

Um dos grandes feitos de Jupyra deu-se no ano de 1952 com a fundação do Conservatório Dramático e Musical. O conservatório é fruto da luta conjunta de Jupyra Cunha Marcondes e seu sobrinho, o deputado federal Mario Eugênio ${ }^{4}$.

Segundo Lins (1974), Jupyra ficou em São Paulo alguns dias, trabalhando em uma sala do Palácio do Governo, redigindo os estatutos e o Regimento Interno que regraria o futuro Conservatório. Toda documentação necessária foi encaminhada para o departamento de Fiscalização Artística do Estado.

\footnotetext{
${ }^{4}$ Mario Eugênio foi deputado federal durante a década de 1920. Além disso, era empresário da área de transporte (MARCONDES, M., 2013). 
Como resultado, Jupyra conseguiu uma concessão da Inspeção Preliminar para o funcionamento da casa de ensino. Andrade (2013) reafirma o empenho de Jupyra em idealizar a escola de artes, mesmo desgastando-se com questões burocráticas, pois “[...] naquela época tinha que ter autorização do Estado, para que escola funcionasse e ela que foi atrás de toda essa papelada em São Paulo várias vezes para que realmente acontecesse o decreto e fosse criado o conservatório".

Quinze de março de 1952. Esta é a data de fundação do Conservatório Municipal Dramático e Musical de Presidente Prudente.

A lei 169 de 15 de março de 1952, decretada pelo então prefeito municipal Domingo Leonardo Cerávolo, dispôs sobre a criação do Conservatório Municipal Dramático e Musical de Presidente Prudente. Dispunha a lei que o conservatório disponibiliza inicialmente os cursos de piano, violino, flauta, harmônica, canto coral, declamação e representação teatral, e para isso deveria contratar corpo docente capacitado para tanto. (LUZ, 2012, p.181)

Segundo Macedo (2013), nesta época só existia instituições e professores que davam aulas particulares de música, e Jupyra decidiu então estabelecer aqui uma escola que não tivesse apenas âmbito musical, mas também outras vertentes artísticas.

Mesmo após a fundação do conservatório, Jupyra continuou a ser grande referência na organização de eventos em prol ao município de Presidente Prudente. Em 1957, por ocasião do Grande Festival em comemoração ao 40으 aniversário da cidade, Jupyra escreveu "Salve, Presidente Prudente" destacando mais uma de suas características: a de escritora (LINS, 1974). No texto, ela enalteceu a cidade que acolheu sua família e sonhos.

Oh! Terra adorada,

Presidente Prudente,

Tú és a namorada

Deste progresso ingente!

O teu desenvolvimento

Paira com brilhante halo

No engrandecimento

De nosso grande e amado S. Paulo! 
(MARCONDES, J., 1957 apud LINS, 1974)

De acordo com Lins (1974), Jupyra permaneceu até 1964 como orientadora artística do conservatório, depois assumiu a direção da escola. Periodicamente eram divulgados na mídia, relatórios semestrais sobre o estado econômico do Conservatório como no dia 5 de Julho de 1956.

A atual diretora da Escola de Artes Professora "Jupyra Cunha Marcondes",, Liliane Junqueira de Andrade (2013) conta como conheceu a fundadora Jupyra. "Eu era estudante do conservatório e passei a fazer substituições como professora, assim comecei a trabalhar na escola pelas mãos da dona Jupyra, que me passava essas substituições para serem feitas." (ANDRADE, 2013).

Dando continuidade ao sonho de Jupyra, a diretora vigente relata como está atualmente a Escola de Artes que leva o nome de sua fundadora. De acordo com ela, a escola trabalha com alunos de cinco a seis anos de idade, que fazem o curso de iniciação musical. Depois disso, eles podem passar para os instrumentos específicos, que são: piano, teclado, instrumentos de cordas, violino, viola caipira, violoncelo, instrumentos de sopro como flauta transversal, trompete, trompa, clarinete e saxofone. Além disso, a escola é a única da cidade que oferece o curso de qualificação profissional (ANDRADE, 2013).

A diretora explica que, para 2013, estão previstas diversas mudanças e novidades, "[...] então nós temos a intenção de ampliar cada vez mais o atendimento pra gente atender cada vez melhor a comunidade, e aí nós temos também o curso de técnica vocal, esse ano o curso de teoria voltado para a percepção da teoria vocal e coral voltado para o pessoal que quer prestar o vestibular e faculdade." (ANDRADE, 2013)

Atualmente, a Escola de Artes Professora "Jupyra Cunha Marcondes" está sob os cuidados da Prefeitura Municipal de Presidente Prudente. Sobre as perspectivas em relação à instituição, o secretário de cultura da cidade Fábio Nougueira (2013) diz que:

Vamos lutar para que tenhamos a primeira turma em 2014, de dois cursos de teatro e dança. Então ela cumpre-se, ela cumpre o objetivo maior dela, que é ser uma escola de artes. Não de uma área específica, no caso a música, mas que já agora tem teatro e dança, que no futuro próximo vai ter outras coisas. Tem o curso de desenho, de pintura, de artesanato, enfim, que seja uma escola aberta para todas as artes. (NOUGUEIRA, 2013)

\footnotetext{
${ }^{5}$ Como homenagem à Jupyra, a Câmara dos Vereadores modificou o nome do Conservatório Municipal Dramático e Musical para Escola de Artes Professora "Jupyra Cunha Marcondes". Macedo (2013) e Andrade (2013) citam a homenagem da Câmara em decorrência da morte de Jupyra. O atual secretário de cultura da cidade Fábio Nougueira (2013) conta como realmente ocorreu a mudança na nomenclatura: "A mudança de conservatório para escola, deu-se pois a palavra conservatório soava de maneira muito rígida e não queríamos esta impressão para a escola, por isso escolhemos Escola de Artes Professora 'Jupyra Cunha Marcondes' e continuamos a homenagear a sua fundadora" (NOUGUEIRA, 2013).
} 
Fábio Nougueira (2013) concorda que é incontestável o que a escola representa. Segundo ele, a escola nasceu a partir do sonho "[...] de uma pessoa, que foi a professora Jupyra. Essa mulher que sonhou que Prudente poderia ter na época um conservatório de música, ela que foi professora, ela que foi a criadora, ela que foi a idealizadora, diretora, enfim, ela foi o grande cérebro de criação."

Jupyra Cunha Marcondes faleceu em 25 de junho de 1974. Consta no atestado de óbito que a morte de Jupyra foi ocasionada por enfisema e embolia pulmonar.

Sua morte foi anunciada no jornal "O Imparcial" e causou consternação na cidade de Presidente Prudente. Em várias edições do jornal, nos dias seguintes a sua morte, é possível conferir mensagens de homenagens, como a crônica intitulada "Dona Jupyra", na edição do dia 28 de junho, escrita pelo aluno Rubens Shirassu em sua coluna "A vida e o tempo".

Sua morte chegou a repercutir até mesmo na Câmara Municipal de Presidente Prudente, como foi informado pelo jornal "O Imparcial" no dia 28 de junho de 1974. Os votos de pesares ficaram registrados em Ata.

O jornalista Altino Correia (2013) declara que uma figura igual à Jupyra Cunha Marcondes faz falta e continua deixando saudades. Para ele, sem dúvida, ela era "uma pessoa dedicada à atividade cultural, artística, e sempre preocupada com a situação, principalmente com a sobrevivência do próximo."

Conceição Alves (2013) acredita "que ela não morreu não. Que ela está viva dentro de mim. Porque uma pessoa que nem a dona Jupyra, não morre jamais".

\section{Processo de produção do videodocumentário}

O videodocumentário foi escolhido como peça prática deste estudo, pois se utiliza de uma linguagem baseada em depoimentos que retratam a realidade para contar uma história sobre pessoa ou evento. Essa perspectiva é adquirida por meio de depoimentos e testemunhos. Mas afinal, qual é o conceito de documentário?

Para alguns, é o filme que aborda a realidade. Para outros, é o que lida com a verdade. Ou que é filmado em locações autênticas. Ou que não tem roteiro. Ou que não é encenado. Ou ainda, que não usa atores profissionais. Estas e outras tentativas simplistas de balizar o terreno vão sendo sucessivamente negadas pelos exemplos de filmes que não se enquadram nelas, mostrando que os limites são arbitrários e criando um labirinto interminável de exceções que acabam por nos levar de volta ao ponto de partida. (DA-RIN, 2004, p. 15) 
Penafria (1999) defende que ao documentar não se mostra apenas a realidade, mas interage-se com ela no intuito de buscar um significado para a mesma.

Este artigo entende, assim como Rossini (2003), que o documentário é um registro e mediação da realidade humana incorporado a diversas formas de linguagens e suas particularidades.

Para Nichols (2010), uma característica dos documentários é que se baseiam em fundamentos dos elementos que o compõem, ou seja, em sua capacidade de registrar o real diante das câmeras e a intencionalidade diante de certo ponto de quem o produz. Segundo o autor, os documentários são um retrato pessoal do cineasta sobre o assunto abordado, de suas perspectivas, experiências e impressões (NICHOLS, 2010).

O termo documentário surgiu em 1926, quando o escocês John Grierson ${ }^{6}$ utilizou essa palavra para analisar o filme Moana, de R. Flaherty, sobre a vida dos polinésios (SQUIRRA, 1993).

Para Labaki (2005), o cinema nasceu documentário, tendo como pioneiros os irmãos Lumière $^{7}$. No entanto, com crescimento do prestígio popular do gênero documental foram surgindo grandes nomes que por décadas representam o gênero, tais como: David W. Griffith. Robert Flaherty, Joris Ivens, John Grierson e Dziga Vertov, pioneiros da não-ficção.

A base da linguagem cinematográfica é a imagem. Ela é a matéria-prima de um filme documental e representa uma tarefa particularmente complexa. A imagem mistura tecnologia e percepção, ou seja, ao mesmo tempo em que é registro de um aparelho automático que reproduz a realidade traz consigo o desejo de seu realizador. (MARTIN, 2005)

Martin (2005) explica que há uma tendência em confundir linguagem com expressão. Para o autor, a impressão é um meio de expressão como a poesia, a música e a pintura. "A linguagem nasceu com o homem". (MARTIN, 2005, p. 23)

Diante das características de captação de som e imagem, Nazareth (2010) apresenta quatro modalidades de representação do cinema documental, são elas: explorativa, de observação, interativa e reflexiva.

Os textos expositivos têm como principal característica a utilização do comentário dirigido ao espectador. A modalidade denominada de observação delimita a atuação do realizador impedindo que interfira na realidade que está sendo observada. Na modalidade interativa, o

\footnotetext{
${ }^{6}$ John Grierson (1898-1972) é um dos principais nomes da história do documentário. Este escocês liderou o Movimento Documentarista Britânico (movimento que marcou as décadas de 30 e 40) e foi o responsável pelo reconhecimento do documentário como um gênero autônomo. (LABAKI, 2005)

7 Nascidos em Besançon, na França, os irmãos Lumière, Auguste Marie Louis Nicholas Lumière e Louis Jean Lumière foram os primeiros a fabricar algo que pudesse registrar um fato em movimento, o cinematógrafo (câmara de filmar). Eles são conhecidos como os pais do cinema. (LUCENA, 2012)
} 
espectador olha o mundo histórico como uma testemunha por meio das cenas dos atores sociais. Por fim, a última modalidade, reflexiva, trata de conscientizar o telespectador em relação à mensagem que é transmitida, deste modo o documentário passa a ser objeto de reflexão (NAZARETH, 2010).

Peça fundamental para o documentário, o entrevistador pode aparecer ou não nas imagens. "Dentro do quadro traz como conseqüência uma divisão de interesse da tela, podendo, em alguns casos, o entrevistador chamar mais atenção do que o entrevistador em cena." (PUCCINI, 2010, p. 69)

Para Puccini (2010), outro fator que pode interferir nas filmagens é o local onde as entrevistas foram agendadas, tanto pelo comportamento dos entrevistados quanto pelas interferências externas.

A iluminação merece atenção dos cineastas, pois em um ambiente que não seja iluminado o suficiente acaba afetando a boa estética do filme. Watts (1990) definiu as imagens como luzes captadas. Para ele, câmeras de vídeo são simplesmente meios de captar a luz. “Assim, como produtor de vídeo, você precisa estar consciente a respeito da luz, porque, em última análise, ela é a matéria-prima com a qual está lidando." (WATTS, 1990, p. 194)

Lucena (2012) alerta que, para captar boas imagens, é preciso estar atento à combinação de enquadramentos, dando vivacidade ao que se vê na tela e também aos princípios básicos de iluminação.

Tão importante quanto às imagens, o tratamento de som constitui a estilística do gênero documental. Neste caso, há cinco possibilidades que se destacam: som direto, som de arquivo, voz over, efeitos sonoros e trilha musical. (PUCCINI, 2010)

Áudio direto é o som captado em situações de filmagem. Neste grupo enquadram-se as entrevistas, depoimentos e dramatizações. O som de arquivo refere-se a filmes, programas, discursos e entrevistas. A terceira categoria trata da voz over, que também está relacionada à situação de filmagens, no entanto, é aquela voz acrescida ao filme durante a edição, conhecida como voz de Deus ou off. Os efeitos sonoros são sons criados durante o processo de edição e sua função é criar uma ambientação para as imagens. Por fim, a trilha musical tanto pode ser obtida em material de arquivo ou composta exclusivamente para o filme (PUCCINI, 2010).

Para captar o áudio, o melhor recurso para os documentários é o microfone de lapela, sobretudo, para as entrevistas paradas, porque por sua sensibilidade de capturar sons, pode registrar ruídos de roupas. Para entrevistas em movimento, o mais recomendado é o microfone 
direcional e para entrevistas realizadas em estúdio, o correto é optar pelos microfones com boom. (WATTS, 1990)

Nodari (2012) estabelece um padrão para a construção de documentários a partir de algumas etapas: a ideia, o argumento, a pesquisa, o roteiro, pré-produção, produção, montagem, finalização e lançamento.

Lucena (2012) defende que todos têm motivações e ideias a toda hora. Nesse sentido, a autora afirma que uma boa tática é recorrer a questões assimiladas no curso de jornalismo como: O que eu quero mostrar? Como eu quero mostrar isso? Por que eu quero mostrar isso? Quem é meu personagem? O que ele vai fazer? Como ele vai agir?

Já na argumentação, seguindo a sua função de mostrar como será o filme, o documentarista deve apresentar uma breve descrição de seus personagens e dos temas abordados. Completam este tópico os detalhes sobre a narrativa e também o ambiente onde serão filmadas as tomadas (LUCENA, 2012).

Nodari (2012) acrescenta que esta pesquisa inicial sobre os elementos do filme é importante porque coloca seus idealizadores em um primeiro contato com o tema a ser abordado e fornece base para as próximas etapas.

Para Field (2001), um roteiro é uma história contada com imagens. “[...] Se o roteiro é uma história contada em imagens, então o que todas as histórias têm em comum? Um início, um meio e um fim, ainda que nem sempre nessa ordem." (FIELD, 2001, p. 2).

A etapa seguinte ao roteiro é a pré-produção. Segundo Kellison (2007), o produtor assume um papel fundamental para a confecção de vídeos. A seu cargo está a responsabilidade de utilizar os talentos do elenco da equipe. Além disso, um produtor precisa conhecer todas as fases do desenvolvimento do vídeo, bem como os seus desafios.

Puccini (2010) ressalta que as pré-entrevistas marcam o primeiro contato entre os documentaristas e suas possíveis fontes. Esse contato tem por objetivo a obtenção das primeiras informações, ou aprofundar naquelas já conhecidas. A exploração de entrevistas é uma das principais características do documentário, por meio delas é que se sustenta a estrutura discursiva.

A fase seguinte corresponde à edição. Para Watts (1999), embora seja um processo demorado, a edição compensa o esforço. O autor faz um cálculo no qual o processo de edição é exatamente o dobro do tempo gasto nas filmagens. A este tempo é acrescido o tempo no qual os cineastas detalham o trabalho e juntam recursos para a edição. 
Apropriando-se dos conceitos acima, foi confeccionado o videodocumentário que revela os resultados da pesquisa sobre a vida e obra de Jupyra Cunha Marcondes.

Os primeiros esforços foram no sentido de entender a linguagem do documentário. Para isso, vários filmes foram assistidos até que fosse possível criar um referencial para o videodocumentário Jupyra.

Uma vez definida a linguagem, a argumentação do filme foi desenvolvida com base em sete macrotemas, que compõem a vida e obra de Jupyra desde a sua infância, a chegada em Presidente Prudente, a nova família, a docência no Colégio São Paulo, o envolvimento com o rádio, a luta pelo conservatório e, por fim, a morte em 1974. Os macrotemas foram apresentados ao espectador por uma vinheta, que aos poucos ia se construindo e sendo finalizada, a partir de uma foto do rosto de Jupyra do ano de 1974. A criação deste desenho ficou a cargo do professor e artista plástico Josué Pantaleão.

Partindo de uma pré-lista que continha aproximadamente 90 fontes citadas no livro de "Jupyra Cunha Marcondes: um esboço biográfico" de Lins (1974) foram selecionadas 23 pessoas entre ex-alunos, amigos, familiares e autoridades culturais que compartilharam suas histórias e ajudaram a organizar os fatos.

As informações colhidas por meio dos depoimentos foram cruzadas com os dados levantados na pesquisa e análise documental realizada no jornal "O Imparcial". Nesta fase, as notícias encontradas sobre Jupyra e sua família também foram incorporadas no referencial teórico. No total, foram localizados aproximadamente 200 textos publicados durante os 35 anos pesquisados.

Depois de finalizadas as entrevistas, a pesquisa bibliográfica e a análise documental, com todo material em mãos, foi escrita a primeira versão do roteiro.

O processo seguinte foi a edição de aproximadamente 50 horas gravadas em material bruto. Neste período também foram criados o videografismo (tarjas, vinhetas, animação de documentos e créditos finais), que compunha o videodocumentário obedecendo a alguns signos, como por exemplo, as rosas e partituras, diretamente relacionados ao objeto de estudo desta pesquisa. As flores remetem a uma das paixões de Jupyra e as partituras à principal atuação da professora.

Além do videografismo, fazem parte do filme Jupyra várias fotografias de arquivo, que ilustraram os depoimentos. Houve também uma preocupação com a trilha sonora que seria 
utilizada. Para isso, a pesquisa se apropriou de músicas de domínio público, previamente selecionadas pelo professor Valter Trevisan, que integra o corpo docente do conservatório.

Depois de dois meses de edição no laboratório de TV da Faculdade de Comunicação Social “Jornalista Roberto Marinho" de Presidente Prudente (Facopp), o filme totalizou 90 minutos de duração. A primeira exibição pública do videodocumentário "Jupyra" foi realizada no dia 22 de maio, na Sala de Cinema Condessa Filomena Matarazzo, no Centro Cultural Matarazzo, em Presidente Prudente. Assistiram ao filme aproximadamente 100 pessoas, entre professores, entrevistados, autoridades locais e os familiares dos pesquisadores.

\section{CONSIDERAÇÕES FINAIS}

Organizar fragmentos da vida e obra de uma mulher que atuou na sociedade prudentina, sobretudo no que diz respeito às questões culturais, por várias décadas do século passado e transformar a informação acessada em um documento com linguagem audiovisual foi o objetivo desta pesquisa. A mulher escolhida como objeto de estudo deste trabalho foi Jupyra Cunha Marcondes.

E quais são as contribuições que Jupyra deixou para o cenário cultural de Presidente Prudente? Com uma pergunta para responder, muitas pessoas foram contatadas para criar o esboço biográfico desta mulher. Os depoimentos de pessoas que a conheceram e autoridades culturais da cidade deixaram implícito que, este trabalho, estava tratando de uma pessoa completamente engajada. Em Presidente Prudente ou em qualquer lugar, ela teria tido a mesma atuação cultural porque seu amor pela cultura vai além das barreiras geográficas. Sorte desta cidade, que tão bem a recebeu e deu condições para que seu trabalho perpetuasse ao longo dos anos.

É inegável o talento de Jupyra em relação às questões culturais, no entanto, o fato de ter se casado com Paulo Kruger Soares Marcondes, prefeito e filho do fundador da cidade, abriu-Ihe portas e fez com que tivesse contato com autoridades que mais tarde lhe ajudariam a realizar seus sonhos (MACEDO, 2013).

Falando de sua atuação como professora de música e língua francesa no "Colégio São Paulo", foi neste espaço que Jupyra teve suas primeiras oportunidades de mostrar o seu trabalho cultural na cidade. Organizando peças teatrais e festas cívicas, extrapolou as barreiras físicas da instituição e por diversas vezes deu aulas e ensaiou seus alunos em sua própria residência (MARINO, 2013). 
O reconhecimento de Jupyra deu-se a partir do momento em que passa a escrever e adaptar radionovelas na Rádio Difusora PRI-5, despertando o interesse da Rádio Tupi e da Rádio Nacional, ambas no Rio de Janeiro. Foi neste período também, que sob a direção artística de Jupyra, pela primeira vez, um programa de Presidente Prudente foi transmitido em São Paulo (BENDRATH, 2013).

No caso das radionovelas escritas e adaptadas por Jupyra Cunha Marcondes, nenhum material sonoro ou registro foi encontrado. Mesmo assim, em alguns momentos os entrevistados do documentário fizeram menção a estes trabalhos que a fez conhecida nacionalmente. (LINS, 1974; MARCONDES, O., 2013; MARCONDES, W., 2013; ALVES, 2013; BENDRATH, 2013)

No entanto, nada se compara aos esforços dispensados por Jupyra para a fundação do Conservatório Municipal Dramático e Musical, considerado por este estudo sua principal contribuição. Foram diversas viagens para São Paulo e reuniões com políticos regionais e estaduais, para que, em 1952, a instituição fosse fundada e proporcionasse a muitos jovens o acesso à cultura por meio da música.

Depois de mais de 60 anos de trabalhos prestados a esta comunidade, o conservatório, hoje com o nome de sua fundadora, se orgulha por sempre se preocupar com a promoção social oferecendo vagas gratuitas aos alunos (ANDRADE, 2013).

Atualmente, estão matriculados mais de 450 jovens que têm contato com uma variedade de instrumentos. E o crescimento é certo. Em breve, a escola deve expandir seu atendimento ao público oferecendo oficinas de artes, não se restringindo apenas à música. Um desejo de sua fundadora (ANDRADE, 2013). De acordo com o atual secretário de cultura, Fábio Nougueira (2013), em 2014, a instituição de ensino deve ampliar sua atuação trazendo cursos de artesanato, teatro e dança.

Muitas das atividades de Jupyra eram divulgadas nas páginas do jornal "O Imparcial" de Presidente Prudente, suas qualidades e esforços eram ressaltados. Por ser filha de Francisco Cunha, fundador do jornal "A Tribuna de Franca" e colunista no jornal prudentino, Jupyra mantinha constante contato com os profissionais da imprensa de Presidente Prudente.

O protagonismo e o envolvimento social de Jupyra na cidade marcaram época e transformaram a vida de todos aqueles que estavam ao seu redor, sejam alunos, amigos e familiares. As conquistas de Jupyra são lembradas até hoje e ela é tida como a mulher que trouxe cultura para Presidente Prudente (SOLLER, 2013; MARTINEZ, 2013; CORREIA, 2013; NOUGUEIRA, 2013; BUCHALA, 2013). 
A pesquisa entende ainda que a linguagem audiovisual foi importante instrumento para organizar o passado e revisar os acontecimentos.

Esgotar este assunto não foi o objetivo desta pesquisa, e sim motivar outras iniciativas científicas, para que por meio de junções de fragmentos históricos de outras personalidades prudentinas, possam ter acesso a fatos até então desconhecidos e que contribuam para um resgate histórico mais abrangente das primeiras décadas da cidade e os muitos cidadãos que aqui construíram sua história.

Espera-se que esta pesquisa contribua para que outros possam compreender a linha de desenvolvimento cultural de Presidente Prudente, que tem suas raízes fincadas nos primeiros anos de sua fundação, com as contribuições de Jupyra.

Pianista ou professora, poeta ou dramaturga, diretora ou escritora. É certo que Jupyra Cunha Marcondes teve várias funções ao longo de sua vida, no entanto, jamais uma definição. $E$ toda tentativa de defini-la será em vão. Toda maneira de quantificar seu trabalho será insuficiente. “[...] Porque uma pessoa que nem a dona Jupyra, não morre jamais." (ALVES, 2013)

\section{REFERÊNCIAS}

ALVES, Conceição de Lourdes Pedrosa. Funcionária da residência. Entrevista concedida a Ivan Oliveira. Regente Feijó. 17 mar. 2013.

ANDRADE, Liliane Junqueira de. Diretora da Escola de artes Jupyra. Entrevista concedida a Ivan Oliveira. Presidente Prudente. 14 mar. 2013.

BENDRATH, Wolfgang Eugênio. Trabalhou na rádio PRI-5. Entrevista concedida a Ivan Oliveira. Presidente Prudente. 20 mar. 2013.

BUCHALA, Riad. Conheceu a família Cunha Marcondes. Entrevista concedida a Ivan Oliveira. Presidente Prudente. 25 mar. 2013.

CORREIA, Altino. Jornalista do interior. Entrevista concedida a Ivan Oliveira. Presidente Prudente. 11 mar. 2013.

DA-RIN, Silvio. Espelho partido: Tradição e transformação do documentário. Rio de Janeiro: Azougue, 2004.

DEMO, Pedro. Metodologia científica das ciências sociais. São Paulo: Atlas, 2000.

ENSINO individualizado, desenvolvimento de competências e habilidades, respeitando o ritmo de aprendizagem de cada aluno, Portal Guia Escolas, 2013. Disponível em: <http://www.portalguiaescolas.com.br/hotsite-colegio-santana>. Acesso em: 16 abr. 2013. 
FIELD, Syd. Manual do Roteiro: os fundamentos do texto cinematográfico. Rio de Janeiro: Objetiva, 2001.

GIL, Antonio Carlos. Como elaborar projetos de pesquisa. 5.ed. São Paulo: Atlas, 2010.

HISTÓRIA de Presidente Prudente. Disponível em:

<http://museu.presidenteprudente.sp.gov.br/historiapp.php>. Acesso em: 30 abr. 2013

KELLINSON, Catherine. Produção e Direção para TV e Vídeo: uma abordagem prática. Rio de Janeiro: Elsevier, 2007.

LABAKI, Amir. É tudo verdade: Reflexões sobre a cultura do documentário. São Paulo: W11, 2005.

LAKATOS, Eva Maria; MARCONI, Maria de Andrade. Fundamentos de metodologia científica. 5. ed. São Paulo: Atlas, 2005

LINS, Maria de Lourdes Ferreira. D. Jupyra Cunha Marcondes: um esboço bibliográfico. Presidente Prudente: Câmara de Vereadores, 1974.

LUCENA, Luiz Carlos. Como fazer documentários. Conceito, linguagem e prática de produção. São Paulo: Summus, 2012.

LUZ, Érica de Campos Vicentini da Luz. A criação do Conservatório Municipal Dramático e Musical de Presidente Prudente - 1952. In: PAULA, Ricardo Pires et al. Presidente Prudente: uma cidade, muitas histórias. Presidente Prudente: Cipola, 2012.

MACEDO, Ronaldo. Historiador de Presidente Prudente. Entrevista concedida a Ivan Oliveira. Presidente Prudente. 19 mar. 2013.

MARCONDES, Mariangela Ferreira da Cunha. Vivendo com Jupyra. Entrevista concedida a Ivan Oliveira. Presidente Prudente. 13 mar. 2013.

MARCONDES, Oswaldo Henrique da Cunha. Segundo filho de Jupyra. Entrevista concedida a Ivan Oliveira. Ribeirão Preto. 26 mar. 2013.

MARCONDES, Washington Luiz da Cunha. $\mathbf{O}$ caçula de Jupyra. Entrevista concedida a Ivan Oliveira. Presidente Prudente. 13 mar. 2013.

MARINO, Maria José. Conviveu com Jupyra. Entrevista concedida a Ivan Oliveira. Presidente Prudente. 20 mar. 2013.

MARTIN, Marcel. A linguagem cinematográfica. Lisboa: Dinalivro, 2005.

MARTINEZ, Hélio. A relação da sociedade e o teatro. Entrevista concedida a Ivan Oliveira. Presidente Prudente. 18 mar. 2013. 
MOREIRA, Sonia Virgínia. Análise documental como método e como técnica. In: DUARTE, Jorge; BARROS, Antonio (Orgs.). Métodos e Técnicas de Pesquisa em Comunicação. 3. ed. São Paulo: Atlas, 2009.

NAZARETH, Adriano José Barbosa Baía. Documento. Documentário... (O gênero a partir de uma ideia). 2010. 224f. Dissertação (Mestrado em Ciências da Comunicação) - Faculdade de Letras da Universidade do Porto. Disponível em: <http://repositorio-aberto.up.pt/handle/10216/55041> Acesso em 13 jan. 2013.

NICHOLS, Bill. Introdução ao documentário. 5.ed. São Paulo: Papirus, 2010.

NODARI, Sandra. A Pesquisa como Fundamento no Roteiro Documentário. 2012. 11p. Trabalho apresentado no DT Comunicação Audiovisual, GP Cinema da Intercom - XII Encontro dos Grupos de Pesquisa em Comunicação, evento componente do XXXV Congresso Brasileiro de Ciências da Comunicação. Fortaleza-CE. Disponível em: <http://www.intercom.org.br/sis/2012/resumos/R70694-1.pdf> Acesso em 12 fev. 2013.

NOUGUEIRA, Fábio. Secretário de Cultura de Presidente Prudente. Entrevista concedida a Ivan Oliveira. Presidente Prudente. 11 mar. 2013.

PENAFRIA, Manuela. Perspectivas de desenvolvimento para o documentarismo. 1999. Disponível em: <http://www.bocc.uff.br/pag/penafria-perspectivas-documentarismo.pdf> Acesso em 13 mar. 2013.

PINTO, Alma Ely Staut Gomes. Nora de Jupyra. Entrevista concedida a Ivan Oliveira. Presidente Prudente. 21 mar. 2013

POLLAK, Michael. Memória e Identidade Social. Estudos Históricos. Rio de Janeiro, v.5, n.10, dez. 1992, p. 200-212.Disponível em: <http://reviravoltadesign.com/080929_raiaviva/info/wp-gz/wpcontent/uploads/2006/12/memoria_e_identidade_social.pdf>. Acesso em: 8 fev. 2013

PUCCINI, Sérgio. Roteiro de documentário: da pré-produção à pós-produção. Campinas: Papirus, 2010.

ROSSINI, Miriam de Souza. O gênero documentário no cinema e na tevê. In: SACRINI, Marcelo. Perspectivas do gênero documentário pela apropriação de elementos de linguagem da TV Digital Interativa. 2003. Disponível em: <http://www.bocc.ubi.pt/pag/sacrini-marcelo-doc-digitalinterativo.pdf>. Acesso em: 20 fev. 2013.

SOLLER, Geraldo. Admiração por Jupyra. Entrevista concedida a Ivan Oliveira. Presidente Prudente. 11 mar. 2013.

SQUIRRA, Sebastião Carlos de Morais. Aprender Telejornalismo: produção e técnica. 2.ed. São Paulo: Brasiliense, 1993.

TAIAR, Neif. Aluno de Jupyra. Entrevista concedida a Ivan Oliveira. Presidente Prudente. 11 mar. 2013. 
Encontro de Ensino, Pesquisa e Extensão, Presidente Prudente, 21 a 24 de outubro, 2013

WATTS, Harris. On Camera: o curso de produção de filme e vídeo da BBC. São Paulo: Summus, 1990.

WATTS, Harris. Direção de Câmera: um manual de técnicas de vídeo e cinema. São Paulo: Summus, 1999. 